Article

\title{
Responsible Design for Sustainable Innovation: Towards an Extended Design Process
}

\author{
Ricardo J. Hernandez ${ }^{1,2, *(D)}$ and Julian Goñi ${ }^{1}$ (D) \\ 1 DILAB Escuela de Ingeniería, Facultad de Ingeniería, Pontificia Universidad Católica de Chile, \\ Santiago 7820436, Chile; jvgoni@uc.cl \\ 2 Escuela de Diseño, Pontificia Universidad Católica de Chile, Santiago 7820436, Chile \\ * Correspondence: rhernandep@ing.puc.cl
}

Received: 20 October 2020; Accepted: 27 November 2020; Published: 29 November 2020

\begin{abstract}
Design as a discipline has changed a lot during the last 50 years. The boundaries have been expanded partially to address the complexity of the problems we are facing nowadays. Areas like sustainable design, inclusive design, codesign, and social design among many more have emerged in response to the failures of the production and consumption system in place. In this context, social, environmental, and cultural trends have affected the way artefacts are designed, but the design process itself remains almost unchanged. In some sense, more criteria beyond economic concerns are now taken into consideration when social and environmental objectives are pursued in the design process, but the process to reach those objectives responds to the same stages and logic as in traditional approaches motivated only by economic aims. We propose in this paper an alternative way to understand and represent the design process, especially oriented to develop innovations that are aligned with the social, environmental, and cultural demands the world is facing now and it will face in the future. A new extended design process that is responsible for the consequences produced by the artefacts designed beyond the delivery of the solutions is proposed.
\end{abstract}

Keywords: design process; innovation; responsible design; sustainable design; sustainable innovation

\section{Introduction}

This article presents a critical discussion on the role of design in society as well as an exploration into how the design process itself may need to be reconsidered in order to comply with the need for a more responsible vision of design for innovation. Design as a discipline has changed a lot during the last 50 years. The boundaries have been expanded partially to address the complexity of the problems we are facing nowadays [1]. To many design practitioners and scholars, design has been one of the most prominent contributors to both the ills that affect society as well as our best shot to overcome them [2-4]. There has also been institutional pressure to reframe our current understanding of design into a more progressive and active agenda. For instance, this has been the case with institutions in the UK such as the Sorrell Foundation, Royal Society of Arts, National Endowment for Science, Technology and the Arts (NESTA), and the Design Council [5].

Overall, these trends aim to vindicate design as a means to overcome the world's challenges by actively avoiding being ideologically neutral and engaging in value-driven activity. Design's areas like sustainable design [6,7], inclusive design [8,9], participatory design [10], social design [11,12], and value-sensitive design $[13,14]$ have sought to change the role of design in society. Learning from the frameworks of responsible innovation [15], we can group all these areas under the label of "responsible designs". We define "responsible designs" as all the wide and heterogenous range of design's areas, approaches, and activities seeking to establish what design ought to be, instead of what it currently is. We define this responsibility extrapolating the work of Voegtlin and Sherer [16] as a tripartite concept: 
(a) the responsibility to avoid harm, (b) the responsibility to good, and (c) the responsible governance of the design process. We assert that all forms of responsible designs ultimately reflect the need to reconsider the criteria of successful design in the face of the global challenges and the responsibility of designers in achieving that success.

In this context, social, environmental, political, and cultural trends have affected the way artefacts are designed, but the design process itself remains almost unchanged. In some sense more criteria beyond economic concerns are now taken into consideration when social and environmental objectives are pursued in the design process, but the process to reach those objectives responds to the same stages and logic as in traditional approaches motivated only by economic aims. For instance, when a product is designed with the objective to be sustainable, the normal approach is to bring principles and considerations from the sustainable design area, and inject them ideally at the start of the design process. There are tools developed to help designers to consider those principles and concerns, but in general the essence of the design process remains unchanged. This situation can be extrapolated to inclusive design, participatory design, social design, and almost all the "responsible designs" we mentioned earlier.

We propose in this paper an alternative way to understand and represent the design process, especially oriented to develop innovations that are aligned with the social, environmental, political, and cultural demands the world is facing now and it will face in the future. A new extended design process that is responsible for the consequences produced by the artefacts designed beyond the delivery of the solutions. We recognize there are multiple models that represent the design process [17-19]. Some of those models have been developed by engineers [18,20,21], others by designers and architects [22,23], some by practitioners and others even by business consultancies [17]. In these models there are different sources of variability associated with the discipline of origin, their orientation to the users, and the scope of the process [19]. However, there are also some common elements that build the structure of the design process. Those elements include the iterative rationality of the process, the divergent and convergent way of thinking embedded in the stages of the process, their orientation towards actions, and the compatibility of the process with a variety of possible outcomes $[19,21,24]$. Between these common elements there is not any one that represents the responsibility the design process should have to assure responsible results.

Learning from the experience of the responsible innovation framework, we observe that an extended design process should include ideals of anticipation, reflexivity, inclusion, and responsiveness [15]. In turn, it implies that design professionals and institutions should develop anticipatory, participatory, and integrative capacities [25]. We argue that an extended design process should have at its very base some of those elements that include the ideals of what we called "responsible designs", not as injections of external concepts but as structural pillars of the process. With this ambition comes also the idea to develop a model that can represent that kind of extended design process.

In sum, this paper is a conceptual article $[26,27]$ that seeks to "provide an integration of literatures, offer an integrated framework, provide value added, and highlight directions for future inquiry" [26] (p. 17) in the intersection of design and responsibility. This added value, directions and propositions are also inspired by many years supervising and guiding design processes, and observing how responsibility is enacted in practice using the most traditional view of design. The aim of this article is twofold. Firstly, to expose the need to reconsider and potentially redesign the mainstream representations of the design process. Secondly, to explore the feasibility to incorporate responsibility into the core of the more traditional view of the design process through a model involving three elements: pertinence, transparency, and distributed agencies.

\section{Responsible Designs}

Current societal challenges put pressure on the design discipline and design professionals to integrate goals and success indicators beyond profit making [11,28]. These challenges involve different aspects of society, for instance, the environmental crisis, rising wealth inequality, ageing and 
over population, human and technology tensions, diminishing quality of life, decolonization and decentralization, and so on.

To many, design has been one of the most prominent contributors of progress, but also to social harm [2-4]. In practice, this has meant that over the past 20 years, the design discipline has sought to be reformulated and updated in order to live up to their aspirations to bring about a better world [29].

Overall, these trends set out to update design as a vehicle for change through value-driven activities. For this reason, we can group all these trends under the label of "responsible designs". We define "responsible designs" as all the wide and heterogeneous range of design trends, approaches, and activities seeking to establish what design ought to be, instead of what it currently is. It is important to note that despite the fact that many of the responsible design trends encompass each other interests. For instance, socially responsible design or sustainable design may incorporate elements of codesign or universal design, but because they belong to differentiated historical roots and have their own conceptual tradition, we concluded that it was best not to give any of these design trends primacy and to categorize all of them under a more neutral label. Figure 1 describes some of the concerns and trends involved in responsible designs:

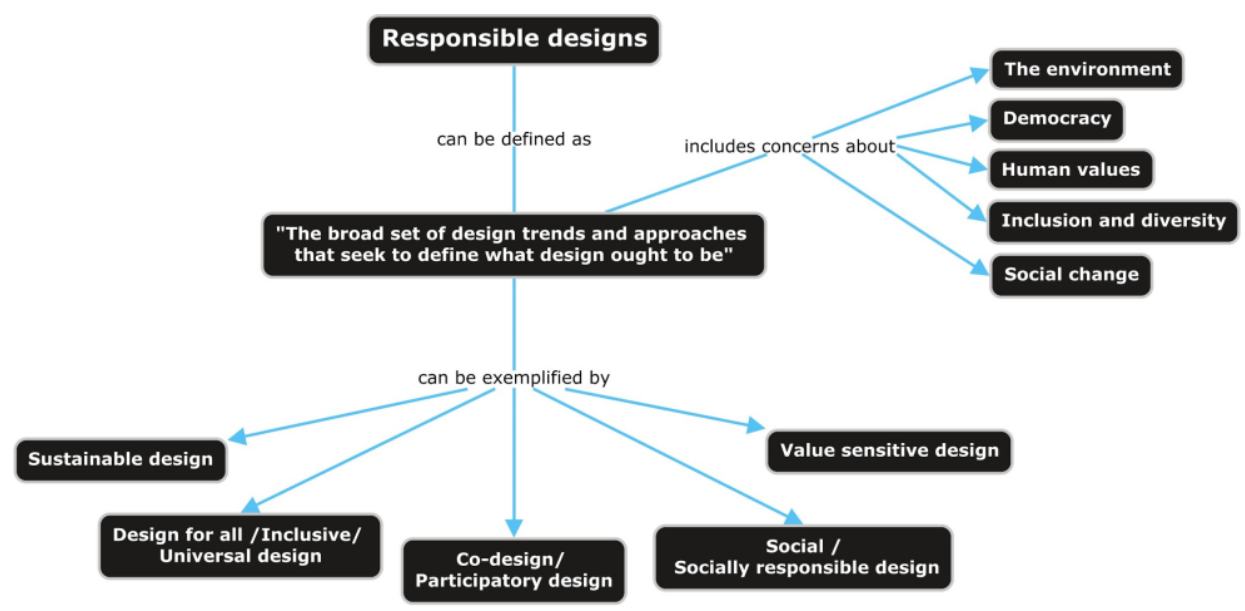

Figure 1. Responsible designs. Original work.

\subsection{Inclusive/Universal Design}

Inclusive design, universal design, accessible design or design for all is a group of design trends that seek to design and redesign products and services to make them accessible and usable to all or at least to a broader set of users [9]. It has mostly centered on issues of age and ability [8], but its underlying principle of universal access can be applied to all forms of individual differences. The idea of inclusive became more prominent in the 50s in the US under the label "Barrier-free design" in response to the difficulties of war veterans with injuries and physical disabilities [9]. Since then, inclusive design has been promoted under antidiscrimination laws both in Europe and the US [30].

\subsection{Codesign/Participatory Design}

Participatory design and codesign approaches are design trends that broadly seek to include all relevant stakeholders into the design process aspiring to equal power to all parts [10,31]. The reasoning behind the involvement of the stakeholders is both practical and political; they know what is best for them and they ought to be heard [32]. Historically, the idea of participatory design can be traced back to Scandinavia in the 70s in the context of the political demands for more democracy and collectivism, labor unions and ideals of social emancipation [33]. 


\subsection{Social Design/Socially Responsible Design}

Social design is a broad label that has been used to characterize design practices that aim at social change or social improvement instead of (solely) financial gains [34]. Social design is typically traced back to Victor Papanek, Nigel Whiteley, and Victor Margolin and particularly to Papanek's book "Design for the real world" [35]. The idea of socially responsible design takes that same principle and extends it further in the sense that it implies that designers not only should design for social change but are ultimately responsible for the societal effects of their creation [12]. Socially responsible design often seeks to integrate the principles of sustainability, universal access, and participatory design as all of those approaches are seen to be constituent of social change [11].

\subsection{Sustainable Design}

Sustainable design or design for sustainability is a relatively new area of study in the design discipline. Following the concerns raised in the 70s and 80s about the negative impact industry and human actions were causing on the environment [36,37], many disciplines and between them design were at the center of the discussion. While it is recognized that industry has produced important benefits for society, it has also produced negative consequences like depletion of natural resources, loss of biodiversity, pollution, social inequalities, among others. In response to these problems from a design perspective emerged approaches first to reduce those negative consequences and more recently to create value in social and environmental dimensions as it created economic value during the design process. Those approaches include cleaner production, eco-design, eco efficiency, sustainable product service systems, design for sustainability, and recently circular economy [6,38-41].

\subsection{Value Sensitive Design}

Value sensitive design (VDS) is a design framework developed by Batya Friedman [13], that seeks to incorporate in a systematic way human values into the development of new technologies, especially in the fields of information systems design and human-computer interactions [42]. The value sensitive design framework emphasizes methods and has since its inception been founded on a defined and formal methodology. VDS is structured as a tripartite methodology of Conceptual, Empirical, and Technical Investigations [14] and a series of design actions devoted to make visible and to manage the human values embedded in new technologies and the cultural forms of life of the stakeholders [43].

\subsection{New Criteria for Successful Design}

Due to all the new and renewed concerns that have been championed by design practitioners, citizens and scholars, the criteria used to define the success and failure of designed artefacts needs to be reconsidered and expanded. Through our revision of responsible design trends, we observe many central concerns that have emerged from different perspectives. As seen in Figure 1, these include: "The Environment", "Democracy", "Inclusion/Diversity", and "Social Change". All of these concerns can be interpreted as emergent criteria to define the quality of design. Melles, Vere, and Misic [11] proposed new criteria to define successful design under a socially responsible design approach that summarize these concerns:

- Need: does the user or community need this product/solution?

- Suitability: is the design culturally appropriate?

- Relative affordability: is the outcome locally and regionally affordable?

- Advancement: does it create local or regional jobs and develop new skills?

- Local control: can the solution be understood, controlled and maintained locally?

- Usability: is it flexible and adaptive to changing circumstances?

- Empowerment: does it empower the community to develop and own the solution?

- Dependency: does it add to third world dependency? 
As can be observed in Melles et al.'s [11] criteria, some elements present in other responsible design traditions are missing in this set of questions. Complementary criteria can also be added to the list when considering other responsible design trends:

- Inclusivity: Will all users be able to profit from this design while respecting their diversities?

- Sustainability: Is the solution socially and environmentally sustainable?

- Value driven: Does it represent the value system of the stakeholders?

Meeting all of these standards may seem overwhelming to designers and may also make us wonder about the nature and extent of the responsibility of designers. To authors, such as Dobson [44] design responsibility should be a change in our professional attitudes towards the challenges of today's world. According to Szenasy [45] the key is understanding that all good design is responsible design, and thus, responsibility should be embedded in disciplinary rigor. According to Thorpe and Gamman [5] designers should be responsive instead of responsible for the outcomes of their work. By this, they mean that designers should accept the uncertainty embedded in complex real-world problems and avoid adopting a paternalistic stance in which the designers portrait themselves as saviors to other communities. According to Cipolla and Bartholo [46] design responsibility means acting where you are, that is, acting inside your own community in a coresponsible and dialogical manner. For Markussen [47], socially responsible designers are concerned with micro- and meso-level life improvements for a confined and marginal group or minorities.

Overall, the premise behind responsible designs is that there is a need to reconsider the ways that design incorporates the question of ethics. The philosopher Glenn Parsons [48] describes the three ways in which today's design incorporates ethics:

1. Designers have to comply with the ethical norms, rules, regulations that constrain their professional activity.

2. Designers also engage in ethics when they decide what to create.

3. The products of the design professionals also change the social landscape and thus, the concept of ethics itself.

The interesting fact about all of those ways in which ethics is embedded into the design practice, is that they act implicitly and are not part of the formal activities in the design process. In other words, the ethics and responsible concerns of design have not been designed into the design process itself. This is not to say that design teams have not incorporated some of the responsible design criteria, but rather that in some cases its incorporation has not substantially altered the overall representation of the stages involved in the design process [49-55]. More than that, these concerns have not been systematically transformed how designers outside the responsible design trends conceive and visualize the stages of the design process, at least not in all cases [56].

\section{Conceptualization of the Design Process}

The design process has been represented historically by different models. Some of them more normative than others, some very detailed, while others are more abstract representations of the process [17-21,57]. It is true that in recent years new ways to represent and to guide the design process have emerged in areas like speculative design, critical design, and design fictions, however, a traditional view of design still remains valid and widely used in industry and independent practice. This traditional view of the design process is usually recognized as solution-oriented, and it is in our interest to build our proposal of an extended design process on this traditional view of the design process.

These solution-oriented models of the design process are characterized by factors coming from different dimensions. One of those dimensions has to do with the discipline of origin. There are models developed by engineers that have a very comprehensive understanding of the resources and the stages involved in the conception and production of an artefact from a functional perspective $[18,20,21]$. 
There are also models developed by designers and architects that respond to other rationality [23], and even models developed by business consultancies and practitioners that address a totally different set of drivers $[22,58]$.

However, the discipline of origin in not the only dimension affecting how the design process is represented, there is also the fact that some of those models represent processes centered in the users while others take a different approach $[24,59]$. The scope of the process is also a source of variability. There are models that consider the design process from the requirements gathering with the users to the final development of the solution including stages of conceptual design, detail design, and even manufacturing $[21,60]$. In contrast, there are more simplified models that consider the design process only as the stages that concerns giving form to a preliminary solution later to be developed by other areas in an organization.

Despite the variability between different models to represent the design process there are some common elements between them that should be remarked. First, there is the notion that the design process is iterative and it is expected to come back from later stages to previous ones in a continuous cycle of improvements [24]. This is true in models with few steps up to very complex representations with multiple stages and substages. Second, it is the divergent and convergent way of thinking embedded in the stages of the process [57]. This logic responds to complementary stages of analysis and synthesis to understand the context and the opportunities of intervention, and also to develop and select the possible solutions. A third common element between different representations of the design process corresponds to their orientation towards action $[23,24,61]$. This means that the models that represent the design process favor a practical approach over a theoretical one. This orientation towards action is capitalized in different moments where the design process gets closer to the user to collect information, to involve them in the process, or to test a solution. Finally, there is a fourth common element between different models of the design process. This common element is the compatibility of the model to be used in very different situations and to produce very varied outcomes. In general, a model of the design process is a representation that can be used to design a table as it can be used to design a car, or even a more complex artefact. The level of detail will be off course different in each case but the general stages that should be followed are basically the same.

Between these common elements in different models that represent the design process there is not one that addresses the responsibility the design process should have to assure responsible results. In this context, we recognize that social, environmental, political, and cultural trends have affected the way artefacts are designed, but the classical and most used design process in its core elements remains almost unchanged. In some sense, more criteria beyond economic concerns are now taken into consideration when social and environmental objectives are pursued in the design process, but the process to reach those objectives responds to the same stages and logic as in traditional approaches motivated only by economic aims. For instance, when a product is designed with the objective to be sustainable, the normal approach is to bring principles and considerations from the sustainable design area, and inject them ideally at the start of the design process. There are tools developed to help designers to consider those principles and concerns [38,62,63], but in general the essence of the design process remains unchanged. This situation can be extrapolated to inclusive design, participatory design, social design, and almost all the "responsible designs" we mentioned earlier. An extended design process that includes elements in its more basic structure that can represent the responsibility the process should have to assure responsible results is needed, especially for solution-oriented processes aiming to develop innovations aligned with social, environmental, political, and cultural objectives.

In the next section we present an analysis of the emergence and evolution of three applications of the Internet of Things (IoT), as examples of innovations developed with some additional criteria in mind that supports our idea of developing a new extended design process. In these examples we highlight some of the elements we believe should be taken into consideration in an extended design process towards responsible innovations. We do not claim these examples are cases of responsible design, not even case studies. The purpose of these examples is to illustrate how the consideration of 
elements such as distributed agencies, pertinence, and transparency can change the dynamics and the results of the design process favoring the reflection on responsible design in a broad sense, and to show how those elements can be manifested in practice. All three examples were selected purposively as documented examples of design within the same theme (i.e., IoT). In these examples we reconstruct the design process and characteristics of the design solution in order to analyze them through the lens of each proposed component of a responsible design process.

\section{Internet of Things (IoT): An Atypical Innovation}

The term Internet of Things (IoT) is relatively new. According to Coulton, Lindley, and Cooper [64], the term "The Internet of Things" was coined by Kevin Ashton. Kevin was executive director of the AutoIDCentre in the MIT in 1999 [65]. The concept of IoT combines previous interest on ubiquitous computing proposed by Mark Weiser [66], the development of sensor technology [67], and the idea of device to device (D2D) communication proposed by Bill Joy [68]. The first documented case of IoT occurred in 1984, when a coke machine was connected to the internet to report the availability and temperature of the drink [69]. Since its proliferation in the 1990s, IoT technology has mostly been used to expedite industrial logistics and since the 2010s has systematically permeated the homes of users [67]. As Sharma, Shamkuwar, and Singh [67] assert, IoT is now much more than installing sensors on objects and calling it "Smart". New IoT developments are increasingly more complex and integrated with other technological trends such as Artificial Intelligence, Big data, Cloud Computing, and Robotics among others.

There are multiple definitions of IoT that include different elements, but that converge to very similar ideas. In the Little Book of Design Fiction for the Internet of Things [64], there is one explanation that covers well the nature and purpose of what is called IoT nowadays:

"we use the term to describe any objects or things that can be interconnected via the Internet, making them to be readable, recognizable, locatable, addressable, and controllable by computers. The things themselves can be more or less anything. Later in the book we use examples such as a kettle, a door lock, an electricity meter, a toy doll, and a television, but it's important to remember that there is no limit on what could be an IoT thing. Anything that is connected to the Internet is arguably part of the IoT, including us." [64]

For the purpose of this paper, we are not interested to debate about the definitions or even the technical characteristics of the IoT. What interested us is to analyze how different artefacts using IoT have been designed, developed, and in some cases implemented or introduced to the market. Understanding artefacts in a wide vision as it is presented by [24], including products, services, and systems. In particular, we are interested in the decisions made during the design process of those artefacts. We want to use those examples to discover and to highlight the elements we believe should be incorporated in an extended design process representing the idea of responsible design absent in current design models.

The following three examples of designs and developments under the IoT umbrella are analyzed to discuss the same number of elements we believe should be included in an extended design process.

\subsection{IBM's Smarter Cities Project}

One of the clearest ways in which the Internet of Things is pushing for transformation in our worldview is through its potent vision of distributed agencies. Just as our everyday devices are becoming connected and their decisions distributed among many different information sources, our lives also seem to become more global and our decisions more dependent on the technologies that we use (our smartphones, google, etc.). However, surprisingly enough, the idea that our minds are somewhat interconnected with our environments and our technological tools is not that new.

Ever since the 1940s, cognitive psychologists and philosophers have discussed the extent to which our thinking and action is occurring "outside our heads". This is what is often called distributed 
cognition. According to Gavriel Salomon [70] there are two forms of distributed cognition: shared cognition and off-loading. Shared cognition occurs when a cognitive process is shared among people in a collaborative activity, while off-loading occurs when a mental process is somewhat externalized to a material object, such as a calculator, a grocery list or even, a smart device. We can see that the distribution that characterizes IoT devices also relates to the characteristics of the individual mind itself. However, how about groups of people, or communities or even cities?

Smart cities are a good example of how design projects seem increasingly distributed. Smart cities are based on the new possibilities generated by IoT to interconnect, monitor, and boost the productivity and responsiveness of all services and user contact points embedded in the city as a system [71]. One of the largest smart city designers is actually a former hardware designer: IBM.

In the 1990s and the early 2000s IBM reportedly was going through a difficult financial time [72]. This ultimately led to a strategic shift from hardware design to consultancy and software and the sale of the PC division to Lenovo by 2004. In this context, and in the midst of the financial crisis Sam Palmisano (IBM's CEO) coined the term "smart cities" in a talk entitled "A Smarter Planet: The Next Leadership Agenda". According to one of the IBM managers at the time "in 2008 the launch of Smarter Planet was not merely the announcement of a new strategy but an assertion of a new IBM's worldview, showing how the world has been changed over the previous decade" [73]. As Wiig [74] puts it, IBM's smarter city strategy is ultimately a techno-utopian vision of the new city.

IBM's proposal was ambitious, they sought to help cities redefine public services, social programs, and public infrastructure using emergent digital technologies. How could they redesign such complex systems? In truth, a closer exploration of IBM's smarter cities projects shows that this designing was a very collaborative and distributed process. IBM partnered with city governments, local universities to tackle the multiple variables involved in the challenge. Sometimes, they had to acquire technologies from smaller size firms and even produce new technologies in their Smarter Cities Technology Center in Dublin where world-class researchers were recruited [71].

IBM's design process was not without challenge. As Scuotto, Ferraris, and Bresciani [73] describe, during the design and implementation of their strategies, IBM managers face notable barriers in collaborating with governments, such as scarce management and technological skills and the overall passive role of the public sector. Another difficulty faced in the implementation of their solutions was the management of Intellectual Property Rights (IPR). IBM managers conditioned the sharing of their intellectual property with public organizations to clear contractual conditions carefully negotiated beforehand [73]. IBM tended to share as little knowledge as possible related to the core competitive capabilities in order to avoid knowledge leaks to other government's partners, but had no issue sharing knowledge in more peripheral activities [73].

Looking at IBM's vision for Smarter Cities we can extract many lessons to be incorporated in the design process. Just as our cities, our digital technology and our mind itself seems to be distributed in nature, so should perhaps be elements of the design process. In the documented cases of IBM smarter cities strategies, we can observe that the redesign of cities services involved the agency of many different stakeholders: partnerships with universities to help in the research phase, active involvement of local authorities to fund but also to place priorities, technology firms of lesser size to provide strategic services and finally, the help of top international researchers through IBM facilities worldwide.

In that sense, the design process of IBM is characterized by a sort of distributed agency-or shared cognition in the words of Salomon [70] — in which actions, burdens, benefits, and properties were negotiated among different actors. We can also learn that even if responsibilities are distributed, they also have to be clear in order facilitate collaboration. Even though the IBM design process is collaborative, it does not mean that, for instance, property rights could be diluted. On the contrary, smarter cities were more likely to succeed if the division of both labor and rights was clear and adjusted to the expectations of all involved actors.

We can also extend the argument even further and also analyze other ways in which responsibility is distributed in the design process. In some sense, users also share a responsibility in how artefacts 
impact society, as they hold the ultimate right to choose how to use them. In the case of Artificial Intelligence, Wong [75] argues that users should no longer be considered just passive agents. It is users that have the power to accept/reject certain artefacts that shape how technologies work with their input of data, they may benefit from others wrongdoing, and their decisions with technology can affect other people or the world. Technologies/artefacts themselves can also be regarded to have an agency.

In sum, when designing responsibility into the design process it seems that the distribution should be considered as a fundamental aspect to incorporate. The design process involves multiple agencies, from the designers themselves to institutions, to stakeholders, to end-users and to the technologies. The boundaries, actions, and properties of that distribution should be arranged at some point, or multiple points of the design process.

\subsection{Smart Labels and IoT Sensing Technologies}

One interesting concept that it is in some sense missing in the conceptualization of the design process is pertinence. It is defined by the oxford dictionary as: "the quality of being appropriate to a particular situation" [76]. Not because something can be made, it should be made. A premise usually ignored in the design and development of artefacts. There are multiple examples of products that actually nobody needs, or even worse products that might harm instead of providing a purposeful function.

Smart packaging and IoT sensing technologies are a good example to talk about pertinence. Smart labels are not a new concept. They have been around for at least four decades [77,78]. These labels use passive technologies like RFID to store a certain amount of information about a product that can be read by specific scanners and facilitates logistics and inventory control [79]. Initially these kinds of technologies were mainly used in warehouses and during transportation of goods to track products along the supply chain. In the earliest 2000, these smart labels were introduced in retail used for similar purposes, to have some level of control over inventories and to make the restock process more expedited. Actually, Walmart, a major US retailer started to request the use of these technologies to their suppliers, something that increased substantially the use of smart labels and decreased its price [77].

During the last two decades the applications of those smart labels have been increased and moved to new environments. In medical services pilots looking to prevent human errors for example in transfusion of blood have been put in place such as the pilot tested in the Massachusetts General in Boston [77]. Additionally, in the pharmaceutical industry they have been used in drugs to prevent counterfeit [80]. The technology has also evolved during this time, from passive labels to active tags that can be connected to the Internet and display a whole new set of capabilities.

Recently, these technologies have been considered to approach the major problems we face today as society, waste management. The amount of waste we produce every day is alarming and with it the loss of valuable resources and materials. Addressing this big issue, smart labels and sensing technology connected to the Internet have been used to design systems that can improve the sorting and disposing of waste, also to facilitate the management of bins and municipal centers of waste collection using sensors and real time data [78]. In parallel, there are people interested in using these technologies in packaging with purposes such as increasing food safety, design of sustainable biodegradable packaging, and also the development of new business models based on big data opportunities [81]. Even applications like including tags in wine bottles that can provide information about their temperature and perfect moment to be drunk. In this case of smart labels, and IoT applied to packaging, there are two issues that catch our attention. First, the fact that these technologies have been evolving from very basic applications to more sophisticated ones at low speeds. Smart labels have been around for about 40 years and yet we do not find all packages in the supermarket are connected to Internet collecting and transferring data. Why? We believe mainly because of costs and because there is not a strong case that supports the investments to use those technologies in everyday products. We hope some reasons behind this slow introduction to massive markets include also questions about the pertinence of doing so. It is not hard to justify the use of these technologies to 
improve the operations in a warehouse or even better to avoid human errors in medical treatments, but what about collecting commercial data from users or to provide information about a product that can be meaningless for the majority.

What is the limit? What should be the criteria to decide the application of these technologies? Do we want to have everyday products in the supermarket collecting and using information about our tastes and routines? As we mentioned earlier not because something can be made it should be made, or in this case not because something can be used it should be used. Pertinence should be one of the basic elements in the design process. It should be the element that makes designers and engineers think if what they are designing is worth it. Is it making good beyond economic considerations? Is there a possible harm involved? Who should decide if something is pertinent to be designed or not? Is it a task designers should take or should be on the market? When should it be decided if a product is pertinent or not? Questions that should be explored during the design process.

\subsection{IoT Door Lock: Imagination Lancaster}

Design IoT products have major issues related to security, privacy, and management of personal information between other dimensions. These issues can be encompassed in a bigger and more general concept, transparency. This is an important term that is usually undervalued in the design process. Transparency is a property of a product, a service, a process, or a system, and it can be linked to different agents. It means for example that a product can be transparent to the users in the way it works and in the negative and positive impacts it can produce [82], but it can also be transparent to investors, or to the community beyond the role of being a user or not.

A good example of how this concept of transparency can be treated in the design process of a product is presented in an experiment done at Lancaster University by PETRAS, an IoT Research Hub [64]. In this experiment the main question behind was how users accept agreements to use IoT products. In general, all products, IoT or not, came with a user agreement that users have to accept if they want to use the product. In the case of IoT products with multiple functionalities what can happen is that one agreement actually is related to many different functions. When a user gives its consent, that consent covers all those functionalities despite the user wanting or not to use all of them [64].

In order to explore this issue, the group of PETRAS used design fiction as a tool to picture a probable situation. They designed an IoT door lock that has multiple functionality including [64]:

- Near field communication (NFC) feature to unlock instead of a key;

- Geofencing (lock and unlock automatically using geographical location);

- Providing guest access via smartphone app;

- Voice activation using an external service like Amazon Echo;

- Connection to If This Then that IFTT to integrate with other systems.

A relevant characteristic of those functionalities is that each one requires to collect and manage different information from the user, and that information has to be stored at different places. For instance, to address the fact that a user should be able to give consent through a product agreement just to the functionalities he wants to use or to the ones he feels comfortable with, in the experiment an Orbit system was proposed [64]. In their own words:

"Orbits are circular infographics which explain, based on what data a system gathers and where it shares it, how identifiable a person might be from this data. The Orbit design uses three concentric circles, where each circle represents data that might be used to identify you. The inner circle represents data on devices you own (like your router, smartphone, or television). The middle circle represents data on servers of companies you know, but where you have no control over the servers (like the server of the lock company, Amazon's Echo servers, or your mail provider). The outer circle represents data on largely unknown 3rd party servers (this might be IFTTT or a marketing company they sold data to)" [64]. 
Basically, what this Orbits app gives to the user is the chance to know in advance what information will be collected by the different functionalities of the product (Door Lock), where the information will be stored, and how identifiable they will be through the information they will give [64]. With this information the users can accept the product agreement at different levels, allowing the product to perform all its functionalities or just the ones the users are comfortable with [64].

The interesting issue behind this example is the fact that artefacts should embed in their design, features that assure transparency to the users. This transparency has to be related to how the artefact works, how safe it is, what the potential impacts it can produce are, and in general all the information required to make an informed decision regarding the ownership and the use of the artefact. Transparency is an umbrella term part of what we recognize as responsible design and cover issues like security, privacy, safety, and ownership.

\section{Extended Design Process}

Between multiple models to represent the design process, especially the solution-oriented design models, the double diamond developed by the Design Council [57] is the one we chose to present the idea of an extended design process. The selection of this model to be used as the basis of our proposal lies on the fact that this model represents well the more commonly used stages in a traditional design process. It integrates the elements we identified in Section 3, elements that we consider transversal to many solution-oriented models proposed during the years. More than a referent, the double-diamond model was selected as it represents a common ground of the stages of the design process usually used in industry, taught in college, and used in many innovation processes. Rather than to propose a totally new disruptive model we aim to change current practice taking advantage of known behaviors and language.

The proposal is divided in two parts, what should happen before the delivery of the artefact (solution), and what we think should happen after the delivery during the use of the artefact. In the next section we explain in detail the implications of an extended design process in these two moments.

\subsection{Before Delivery}

The Double Diamond design model proposes two consecutive diamonds each one made of one divergent and one convergent stage. In this process the four stages are named as discover, define, develop, and deliver [57]. The first declaration we made, despite that it seems implicit in the model, is that the first two stages in the first diamond relates to the formulation of the design problem, and the third and fourth stages in the second diamond correspond to the development of the solution, see Figure 2.

Then, the major change is to open in the middle of each diamond a space for a new stage. These stages are neither divergent nor convergent, they are included to be evaluation and reflexion points in the design process. Instead of inserting criteria for example of sustainable or inclusive design at one of the original four stages, we propose to have dedicated moments in the design process to make a holistic evaluation of the context and the solutions in relation with the elements we believe represent well what is behind the idea of responsible design: distributed agencies, transparency, and pertinence.

In the first stage of reflexion and evaluation during the formulation of the problem (first diamond) the elements that should be included are transparency and pertinency. The transparency should be oriented to assure that all possible actors, stakeholders, and interactions have been taken into account to build the context in which an area of intervention (opportunity) will be defined. In the example of the Door Lock presented in Section 4 this should refer to consider all the actors that should give and access data during the design and use stages. All the possible relationships between those actors should be mapped and any potential conflict anticipated. The pertinence refers to evaluatin the purpose and relevance of the context built in relation to a set of criteria defined by the areas that delimits a responsible design like sustainability, inclusion, safety, and more depending on each situation. Referring to the example of Smart Labels, it is at this stage that the relevance of the context in which the design should 
take place should be evaluated according not only to economic concerns but arguments from a social and environmental perspective. Finally, distributed agencies are reflected in the strategies used to engage multiple stakeholders in the problem identification and framing. This form of distributed agency relates strongly to the advances and tools originated in codesign/participatory design.
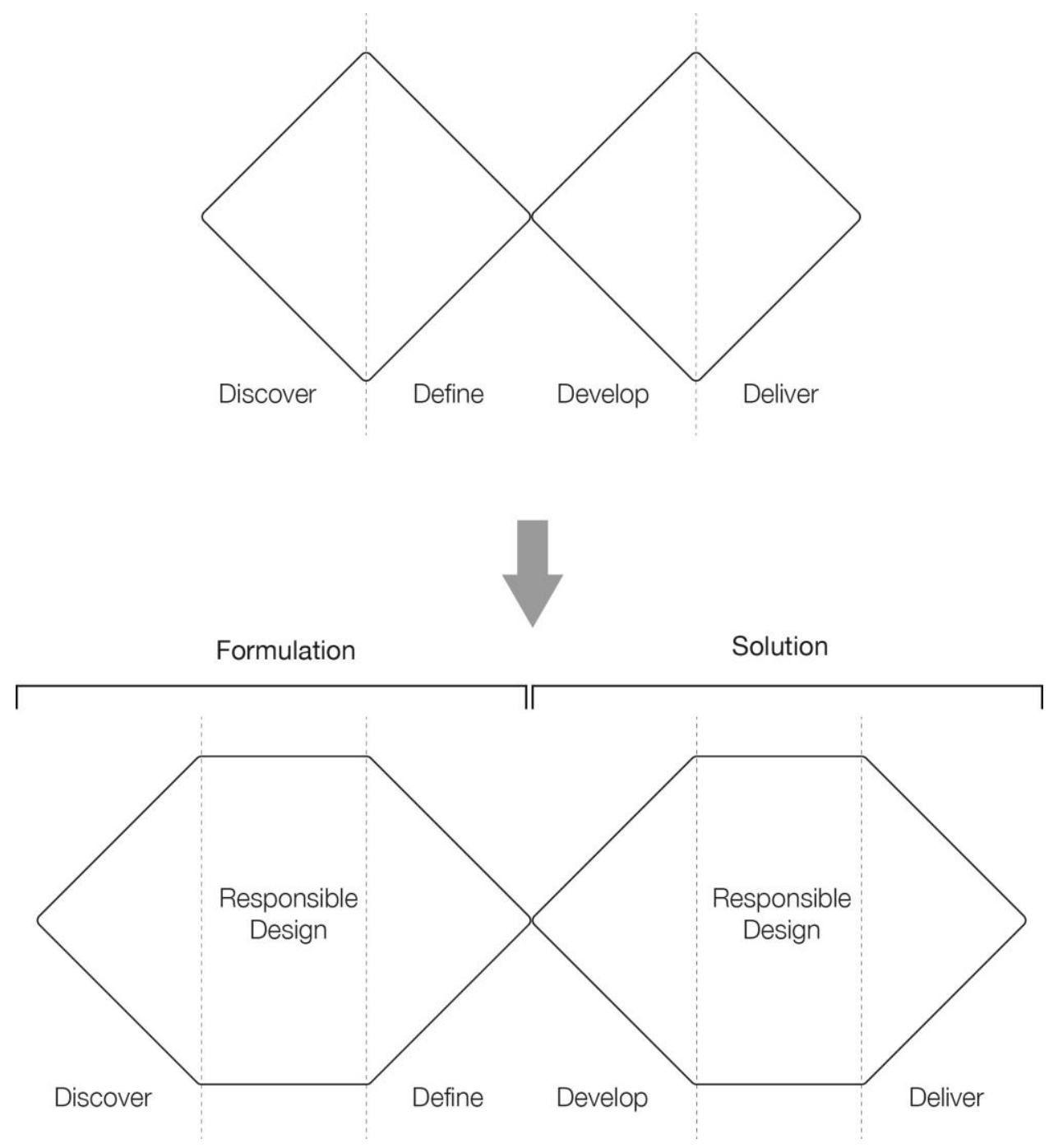

Figure 2. Responsible design before delivery. Original work adapted from [57].

In the second stage of reflection and evaluation during the development of the solution (second diamond) the elements that should be included are transparency, pertinency, and distributed agency. In this case the transparency refers to the information shared by the designers to all the actors and stakeholders that will be involved with the solution. This information includes the way the solution was made, the impacts generated during its development and the impacts it might produce during its use and final disposal, and the requirements of data to operate the solution, between others. The pertinence relates to the relevance and fulfilment of the purpose of the solution. This can be evaluated using for example the set of questions proposed by Melles, Vere, and Misic [11], regarding need, suitability, relative affordability, advancement, local control, usability, empowerment, and dependency; complemented by questions on inclusivity and sustainability. In the two examples mentioned earlier, Door Lock and Smart Labels, this stage of reflection and evaluation should focus on interrogating the solutions developed before any release to the market. This interrogation should address any potential problem during the use of the solutions, like the fact the user should have to give data they do not want to share as it was the case in the Door Lack example, or any possible misinterpretation of 
information given by the Smart Labels that could derive into misuses that could harm the user or others involved. Finally, a third element we believe should be included in this second stage of evaluation is the distributed agencies. It means the assignment of responsibilities between all the agents that will be involved with the solution. These agents include designers, producers, users, communities, and any other one that might be affected directly or indirectly by the solution.

\subsection{Beyond Delivery}

There seems to be a limit to the extent that our imagination can predict or anticipate the future impact of our design solutions. Additionally, this is not just a statement about the abilities and skills or even tools that may help professionals do a better job anticipating, but rather a statement about the nature of the design problems themselves. According to Rittel and Webber [83], designers usually have to deal with complex problems that cannot simply be addressed in a straightforward way using conventional problem-solving methods that could be applied to structured situations such as natural science experiments, finite solutions games such as chess or engineering optimization problems with a definite answer. Design problems usually resist such rationalistic approaches because they are characterized by blurred boundaries, conflicting information, and systemic complexities. This is what Rittel and Webber denominate "wicked problems" in opposition to "tame problems" that could define other disciplines such as the hard sciences.

Wicked problems are also defined by their unforeseeable impact in the systems they are implemented in. As Rittel and Webber [83] assert: "there is no immediate and no ultimate test of a solution to a wicked problem" (p. 163). Tame problems, on the other hand, have relatively predictable consequences and thus impact evaluation may be conducted. Design solutions to wicked problems produce different sorts of consequences that take place over different periods of time (short, middle, and long term). Therefore, as a final judgement would require all consequences to have played out and as there is no strict time limit for this to happen, an impact evaluation becomes a wicked problem itself. We could extract two different conclusions from this: one may think that this wicked nature of the impact of design solutions prevents us from attempting to assess its impact, but that approach would be conflicting with the adoption of a more responsible vision for design. Another way of looking at it is to deal with this challenge in a more comprehensive and designerly way to assess the impact of our design solution in recognition that they will most likely produce unexpected outcomes in their use, that are somewhat unforeseeable during the design process and that all evaluations are to be considered provisional. Our argument is that to achieve this goal, we will be required to extend the design process beyond delivery and to design in more detail how this evaluation is to be conducted.

However, what are the impacts of design? As Kiran [84] asserts, designers ultimately aim at changing behaviors. Through their solutions, designers aim at altering user behaviors through different mechanisms, such as invitation or seduction (e.g., a fly sticker at an airport bathroom that invites biological men to point correctly when they pee) or through inhibition and coercion (e.g., a mandatory seatbelt in our cars). In that sense, learning (i.e., behavioral change) is the direct impact of design.

Designs, however, not only have a direct impact on the user, but in the social and environmental system as a whole. Boenink, Swierstra, and Stemerding [85] argue that the effects of technology can be categorized under two different concepts:

1. Hard impacts: These are quantifiable impacts relating to the observable risk/benefits that agents of the system are exposed to because of the incorporation of the technology.

2. Soft impacts: These are subtle changes in the distribution of social roles and responsibilities, moral norms and values, or social identities that are produced because of the incorporation of the technology.

These two categories can also be broadly applied to design [84]. We can seek to assess how design solutions impact the direct user behavior and the hard and soft impacts they produce in the overall 
system. However, this impact cannot simply be forecasted during the development of the solution, as the wicked nature of the problems will unveil its consequences in use and through time.

It is for that reason that we propose that a more responsible design process should extend beyond the delivery of the solution (as most versions of the design process models do end). An extended design process would although not aim at producing a summative evaluation of the solution as this seem to be impossible, but rather, at monitoring and learning from the unfolding of the design's impact in the system as a means to decide whether it is responsible to maintain the current design, accelerate, pivot, change, fix, reconsider or even in some extreme instances, to stop it.

The criteria used to evaluate our design solutions could be essentially the same that we define as our criteria for pertinence. As we have stated, we believe that the set of questions proposed by Melles, Vere, and Misic [11] that we have expanded in the previous section could serve as a guide for this evaluation. Designers could additionally ask themselves about the unintended consequences of their solutions in practice-both positive and negative - and what they can learn and extract from observing its impact on behaviors, soft and hard transformations in the system. Transparency in this stage would also be necessary. Transparency beyond delivery allows for accountability. Designers should define and communicate how the artifact will be monitored and how that feedback will be managed. Finally, distributed agencies beyond delivery relates to who will do the monitoring. A distributed monitoring could involve individual users, communities, NGOs, Universities, and even governmental agencies depending on the complexity of the project. For instance, the impact of a project such as IBM's Smart Cities should be distributedly monitored by different actors, including the company itself but also through governmental agencies, independent evaluators and potentially the citizens that are affected by the outcomes of this design process. All these partnerships are embedded in dynamics of power and politics that add to the complexity of the design process.

We ultimately believe that the form that the monitoring and learning process beyond the delivery to take place is something that each design team will have to 'design' themselves. We do believe that regardless of the definitive form that design teams will choose, they will have to address at least these three questions:

1. How many monitoring and learning instances will be included?

2. How long into the use of the design will be considered sufficient?

3. What actors will be involved in the monitoring and learning process?

In the end, the complete proposal presented in Figure 3, shows the transversal elements we believe should be included in an extended design process oriented towards the design and development of responsible solutions. In this proposal, besides the appearance of the elements mentioned, pertinence, transparency, and distributed agencies, there are other important remarks. First, the fact that we believe the monitoring of the solutions beyond its delivery to the market should give feedback to the design process and affect any further development of the same solution or new versions of it. Second, the monitoring after the solution (artefact) is delivered should happen at different moments. It is not necessarily a continuous evaluation, neither at equal intervals of time. A major issue in this extended design process as it was mentioned earlier is to define who should do this monitoring, when, and for how long after the solution is delivered. Finally, another important feature in this proposal of an extended design process is the articulation of the two parts (before delivery and beyond delivery), the evaluation and reflection during the first part, before the delivery of the solution, should orient the monitoring during the second part, beyond the delivery of the solution. 


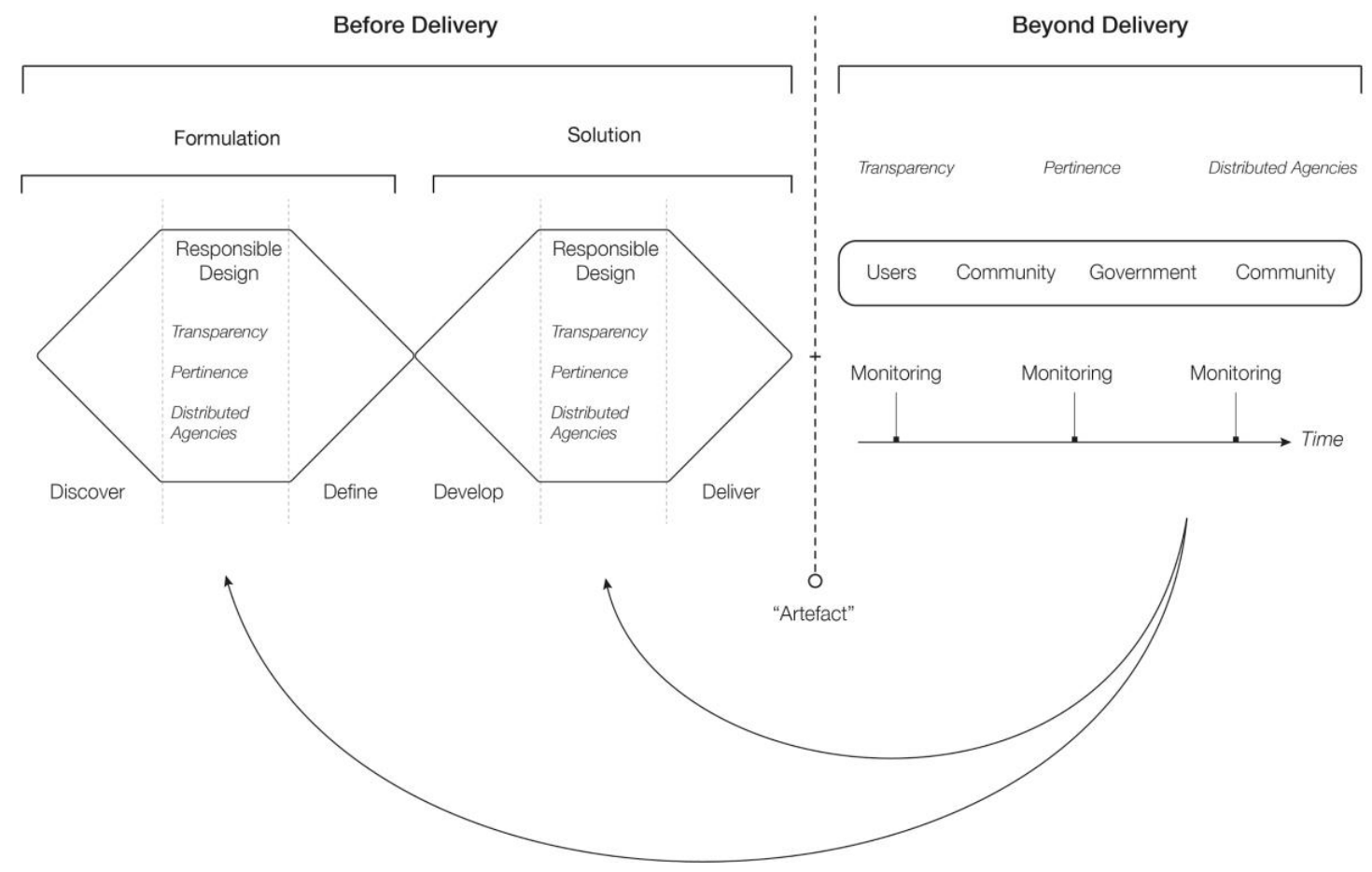

Figure 3. Responsible design before delivery. Original work adapted from [57].

\section{Discussion}

There are many topics we would like to discuss around this proposal of a new extended design process and its representation. Considering the scope of the paper we will summarize them in two issues. First, we would like to discuss the elements we believe represent well the ideas behind a responsible design and the fact that they are not necessarily an exhaustive list. Second, we would like to talk about an additional element we believe should be considered in an extended design process, proportionality.

Regarding the three elements we included in this proposal of an extended design process, distributed agencies, transparency and pertinence, we believe they represent well the main ideas behind the concept of responsible designs, but there might be others. This means that we accept that other elements can be included in the stages of reflexion and evaluation in the two diamonds of the model of the design process used to explain the additions. Any further elements that will be included in the extended design process should respond to the logic of being pillar elements and not specific topics regarding particular contexts. For example, in the field of sustainable design an important issue is to avoid the use of dangerous materials. Beyond the importance of this issue for the evaluation of a sustainable design, this is not a basic element that represents transversally the idea of responsible design, and in consequence it should not be one of the structural elements of the extended design process.

In relation with the second issue of discussion, we believe proportionality should be a theme that has to be taken into account in the development of an extended design process. Both before and after the delivery, we assert that there are many questions and decisions that design teams will have to answer for themselves in order to engage in a more responsible design process. It is not our ambition to provide specific answers, but rather, to suggest some key questions that we think are helpful to facilitate that decision-making process. We do believe, however, that in order to make those decisions, is it important to keep in mind a principle of proportionality. With proportionality we refer to the fact that now a model of the design process like the double diamond presented by the design council [57], is used indistinctly to guide the design of a chair as it is used to design a car, or a service like a financial loan. These three "artefacts" are by nature very different between them, and have different impacts in their fabrication, use, and final disposal. In this context we believe a model that wants to 
represent a responsible design process should consider the scale of the process and the scale of the resulting solution.

In our view, applying a principle of proportionality means that designers should consider the degree of complexity (i.e., the sensibility of the problem, the scale of the solution, the forecasted impact in the system after delivery, etc.) when seeking to design their own design process. As a rule of thumb, we propose that the more complexity, the more responsibility. Of course, as all rules of thumb, this is not an exact science and each case is different, as are the designers themselves. We are not sure yet how to include this element in our proposal, then we expose this topic as a future line of work open to receive ideas and propositions from other researchers working in the area.

As we have asserted, the impact of design is ultimately unpredictable. This should not lead to pessimism or the desire to abandon all attempts for a responsible governance of the design process. Collingridge [86] classically proposed the idea of a "dilemma of control" in technology, but it can also be applied for many of the wicked design problems. Collingridge's dilemma [86] is sustained in two premises:

1. Impacts cannot be easily predicted until the technology has been implemented and widely used. 2. Controlling or governing technology is hard when it has become entrenched in the system.

Both these premises seem to be correct and although it paints a bleak picture for design responsibility, we can look at it as a design challenge. We need to design the design process in order to improve our ability to make better judgments and predictions about the impact of our solutions and to plan how to learn and change as it is being implemented in a system.

Our argument for an extended design process also contests some of the current assumptions that including anticipation and reflexivity are good enough as the basis of responsibility in innovation [15,25]. This is not to say that they are not important, but rather, to state that in order to enact those principles, they have to be designed into the process itself. Additionally, sometimes that means defining their limits (for instance, monitoring in use cannot be replaced solely by anticipatory exercises).

In sum, the path to develop a new extended design process will need to address serious ethical and sociotechnical design challenges. For instance: (a) Dimensionality: what are the new dimensions of responsibility (e.g., pertinence and transparency) that would need to be incorporated? (b) Temporality: when does the design process end? (c) Agency: which actors need to be responsible for what elements of the extended design process? (d) Tooling: what design tools need to be created to mediate and facilitate the extension of the design process?

The projections of this work are multiple. Our next research steps involve first developing our proposals of pertinence, transparency, and distributed agencies further. This means that we will set out to operationalize them through concrete activities, tools, and indicators of success for every new step of the extended design process. Afterwards, we will seek to assess these initial ideas through the analysis and documentation of an implementation with real-life design teams. In this article we explore the issue of ethics in the design process, but as we noted throughout this exposition, there are other neighboring dimensions that could potentially be explored further, for instance, the role of power and politics, the education of future designers, and how technical knowledge relates to ethical concerns during the design process. We expect that by framing the challenges of responsible design and by attempting some initial ideas to extend the design process, we will ignite new debates and confrontations on the current state of the design process.

Finally, the limitations of this proposal must be kept in mind. Most importantly of all, as a conceptual article, we sought to frame the challenges with mainstream representations of the design process and offer a possible model that ultimately serves as proof of the possibility to reimagine the design process. As such, this article lacks the systematic empirical evidence that should support a more definitive extension of the design process. We hope that this initial exploration will ignite further explanations to show the roots and rationale of adapting this existing process, as well as systematic evidence pointing out strategic and comprehensive ways to incorporate responsibility into the core of the design process. 
Author Contributions: Conceptualization, R.J.H. and J.G.; writing-original draft preparation, R.J.H. and J.G.; writing-review and editing, R.J.H. and J.G. All authors have read and agreed to the published version of the manuscript.

Funding: This research received no external funding.

Conflicts of Interest: The authors declare no conflict of interest.

\section{References}

1. Hernandez, R.J.; Cooper, R.; Jung, J. The understanding and use of design in the UK industry: Reflecting on the future of design and designing in industry and beyond. Des. J. 2017, 20, S2823-S2836. [CrossRef]

2. Margolin, V.; Margolin, S. A “Social Model” of Design: Issues of Practice and Research. Des. Issues 2002, 18, 24-30. [CrossRef]

3. Papanek, V. Design for the Real World: Human Ecology and Social Change, 2nd Revised ed.; Thames \& Hudson: London, UK, 1991.

4. Whiteley, N. Design for Society; Reaktion Books: London, UK, 1993.

5. Thorpe, A.; Gamman, L. Design with society: Why socially responsive design is good enough. CoDesign 2011, 7, 217-230. [CrossRef]

6. Bhamra, T.; Lofthouse, V. Design for Sustainability: A practical Approach; Cooper, R., Ed.; Gower Publishing Limited: Hampshire, UK, 2007.

7. Margolin, V. Design for a Sustainable World. Des. Issues 1998, 14, 83-92. [CrossRef]

8. Bichard, J.-A.; Coleman, R.; Langdon, P. Does My Stigma Look Big in This? Considering Acceptability and Desirability in the Inclusive Design of Technology Products. In Proceedings of the International Conference on Universal Access in Human-Computer Interaction, Beijing, China, 22-27 July 2007; pp. 622-631.

9. Persson, H.; Åhman, H.; Yngling, A.A.; Gulliksen, J. Universal design, inclusive design, accessible design, design for all: Different concepts-One goal? On the concept of accessibility-Historical, methodological and philosophical aspects. Univers. Access Inf. Soc. 2015, 14, 505-526. [CrossRef]

10. Robertson, T.; Simonsen, J. Challenges and Opportunities in Contemporary Participatory Design. Des. Issues 2012, 28, 3-9. [CrossRef]

11. Melles, G.; de Vere, I.; Misic, V. Socially responsible design: Thinking beyond the triple bottom line to socially responsive and sustainable product design. CoDesign 2011, 7, 143-154. [CrossRef]

12. Cooper, R. Ethics and Altruism: What Constitutes Socially Responsible Design? Des. Manag. Rev. 2010, 16, 10-18. [CrossRef]

13. Friedman, B. Human Values and the Design of Computer Technology; Cambridge University Press: New York, NY, USA, 1997.

14. Friedman, B.; Hendry, D.G.; Borning, A. A Survey of Value Sensitive Design Methods. Found. Trends Hum. Comput. Interact. 2017, 11, 63-125. [CrossRef]

15. Stilgoe, J.; Owen, R.; Macnaghten, P. Developing a framework for responsible innovation. Res. Policy 2013, 42, 1568-1580. [CrossRef]

16. Voegtlin, C.; Scherer, A.G. Responsible Innovation and the Innovation of Responsibility: Governing Sustainable Development in a Globalized World. J. Bus. Ethics 2017, 143, 227-243. [CrossRef]

17. Dubberly, H. How Do You Design? A Compendium of Models; Dubberly Design Office: San Francisco, CA, USA, 2004.

18. Pugh, S. Total Design: Integrated Methods for Successful Product Engineering; Addison-Wesley: Boston, MA, USA, 1991.

19. Wynn, D.; Clarkson, J. Models of designing. In Design Process Improvement: A Review of Current Practice; Springer: Berlin/Heidelberg, Germany, 2005; pp. 34-59.

20. French, M. Conceptual Design for Engineers; Springer: Berlin/Heidelberg, Germany, 1999.

21. Ulrich, K.; Eppinger, S. Product Design and Development; McGraw-Hill: Boston, MA, USA, 2003.

22. Brown, T. Change by Design (Google eBook); Harper Collins: New York, NY, USA, 2009; ISBN 0061937746.

23. Cross, N. Design Thinking: Understanding How Designers Think and Work, 1st ed.; Berg Publishers: Oxford, UK; New York, NY, USA, 2011.

24. Ulrich, K.T. Design: Creation of Artifacts in Society; University of Pennsylvania: Philadelphia, PA, USA, 2011; ISBN 978-0-9836487-0-3. 
25. Fisher, E. Reinventing responsible innovation. J. Responsible Innov. 2020, 7, 1-5. [CrossRef]

26. Gilson, L.L.; Goldberg, C.B. Editors' Comment: So, What Is a Conceptual Paper? Gr. Organ. Manag. 2015, 40, 127-130. [CrossRef]

27. Hulland, J. Conceptual review papers: Revisiting existing research to develop and refine theory. AMS Rev. 2020, 10, 27-35. [CrossRef]

28. Stevenson, N. A Better World by Design? An Investigation Into Industrial Design Consultants Undertaking Responsible Design Within Their Commercial Remits; Loughborough University: Loughborough, UK, 2013.

29. Margolin, V. Social design: From utopia to the good society. In Design for the Good Society; Bruinsma, M., van Zijl, I., Eds.; Stichting Utrecht Biennale: Utrecht, The Netherlands, 2015; pp. 28-42.

30. John Clarkson, P.; Coleman, R. History of Inclusive Design in the UK. Appl. Ergon. 2015, 46, $235-247$. [CrossRef]

31. Hartson, R.; Pyla, P. Background: Design. In The UX Book; Elsevier: Amsterdam, The Netherlands, 2019; pp. 397-401.

32. Simonsen, J.; Robertson, T. (Eds.) Routledge International Handbook of Participatory Design; Routledge: London, UK, 2012.

33. Huybrechts, L.; Benesch, H.; Geib, J. Institutioning: Participatory Design, Co-Design and the public realm. CoDesign 2017, 13, 148-159. [CrossRef]

34. Koskinen, I.; Hush, G. Utopian, molecular and sociological social design. Int. J. Des. 2016, 10, 65-71.

35. Papanek, V. Design for the Real World; Van Nostrand Reinhold: New York, NY, USA, 1984.

36. Meadows, D.; Meadows, D.; Randers, J.; Behrens, W. The Limits to Growth: A Report for the Club of Rome's Project on the Predicament of Mankind; Pan Books Ltd: London, UK, 1972.

37. WCED. Our Common Future; Oxford University Press: Oxford, UK, 1987.

38. Bhamra, T.; Hernandez, R.J.; Mawle, R. Sustainability: Methods and Practices. In The Handbook of Design for Sustainability; Bloomsbury Publishing Plc: London, UK, 2013; pp. 106-120.

39. Brezet, H.; Van Hemel, C. Ecodesign: A Promising Approach to Sustainable Production and Consumption; United Nations Environmental Programme (UNEP): Nairobi, Kenya, 1997.

40. Hernandez, R.J. Sustainable Product-Service Systems and Circular Economies. Sustainability 2019, 11, 5383. [CrossRef]

41. Hernandez, R.J.; Bhamra, T.; Bhamra, R. Sustainable Product Service Systems in Small and Medium Enterprises (SMEs): Opportunities in the Leather Manufacturing Industry. Sustainability 2012, 4, 175-192. [CrossRef]

42. Friedman, B.; Kahn, P.H.; Borning, A.; Huldtgren, A. Value Sensitive Design and Information Systems. In Early Engagement and New Technologies: Opening up the Laboratory; Doorn, N., Schuurbiers, D., van de Poel, I., Gorman, M.E., Eds.; Springer Netherlands: Dordrecht, The Netherlands, 2013; pp. 55-95.

43. Winkler, T.; Spiekermann, S. Twenty years of value sensitive design: A review of methodological practices in VSD projects. Ethics Inf. Technol. 2018. [CrossRef]

44. Dobson, A. Environmental citizenship: Towards sustainable development. Sustain. Dev. 2007, 15, $276-285$. [CrossRef]

45. Szenasy, S. Ethical Design Education: Confessions of a Sixties Idealist. In Citizens Designer. Perspectives on Design Responsibility; Heller, S., Vienne, V., Eds.; Allworth Press: New York, NY, USA, 2003; pp. 20-24.

46. Cipolla, C.; Bartholo, R. Empathy or Inclusion: A Dialogical Approach to Socially Responsible Design. Int. J. Des. 2014, 8, 87-100.

47. Markussen, T. Disentangling 'the social' in social design's engagement with the public realm. CoDesign 2017, 13, 160-174. [CrossRef]

48. Parsons, G. The Philosophy of Design; Polity Press: Malden, MA, USA, 2016.

49. Barbera, E.; Garcia, I.; Fuertes-Alpiste, M. A Co-Design Process Microanalysis: Stages and Facilitators of an Inquiry-Based and Technology-Enhanced Learning Scenario. Int. Rev. Res. Open Distrib. Learn. 2017, 18. [CrossRef]

50. Lucero, A.; Vaajakallio, K.; Dalsgaard, P. The dialogue-labs method: Process, space and materials as structuring elements to spark dialogue in co-design events. CoDesign 2012, 8, 1-23. [CrossRef]

51. Jarke, M.; Klamma, R.; Pohl, K.; Sikora, E. Requirements Engineering in Complex Domains. In Graph Transformations and Model-Driven Engineering; Springer: Berlin/Heidelberg, Germany, 2010; pp. 602-620. 
52. Li, W.-T.; Ho, M.-C.; Yang, C. A Design Thinking-Based Study of the Prospect of the Sustainable Development of Traditional Handicrafts. Sustainability 2019, 11, 4823. [CrossRef]

53. Wang, S.H.; Chang, S.-P.; Williams, P.; Koo, B.; Qu, Y.-R. Using Balanced Scorecard for Sustainable Design-centered Manufacturing. Procedia Manuf. 2015, 1, 181-192. [CrossRef]

54. Sya'bana, Y.M.K.; Sanjaya, K.H.; Muharam, A. Ergonomie assessment on charging station touch screen based on task performance measurement. In Proceedings of the 2017 International Conference on Sustainable Energy Engineering and Application (ICSEEA), Jakarta, Indonesia, 23-24 October 2017; IEEE: Piscataway, NJ, USA, 2017; pp. 8-13.

55. Schulz, T.; Fuglerud, K.S.; Arfwedson, H.; Busch, M. A Case Study for Universal Design in the Internet of Things. In Universal Design 2014; IOS-Press: Lund, Sweden, 2014; pp. 45-54.

56. Waidelich, L.; Richter, A.; Kolmel, B.; Bulander, R. Design Thinking Process Model Review. In Proceedings of the 2018 IEEE International Conference on Engineering, Technology and Innovation (ICE/ITMC), Stuttgart, Germany, 17-20 June 2018; IEEE: Piscataway, NJ, USA, 2018; pp. 1-9.

57. Design Council. Design for Innovation: Facts, Figures and Practical Plans for Growth; Design Council: London, UK, 2011.

58. Brown, T. Design Thinking. Harv. Bus. Rev. 2008, 86, 84-92.

59. Cross, N. Engineering Design Methods: Strategies for Product Design, 2nd ed.; Wiley: Chichester, UK; New York, NY, USA, 1994; ISBN 978-0471942283.

60. Cooper, R.G. Stage-Gate Systems: A New Tool for Managing New Products. Bus. Horiz. 1990, 33, 44-54. [CrossRef]

61. Cross, N. The nature and nurture of design ability. Des. Stud. 1990, 11, 127-140. [CrossRef]

62. Brezet, H. Dynamics in ecodesign practice. Ind. Environ. 1997, 20, 21-24.

63. Hernandez, R.J.; Brissaud, D.; Mathieux, F.; Zwolinski, P. Contribution to the characterisation of eco-design projects. Int. J. Sustain. Eng. 2011, 4, 301-312. [CrossRef]

64. Coulton, P.; Lindley, J.; Cooper, R. The Little Book of Design Fiction for the Internet of Things; Lancaster University: Lancaster, UK, 2018.

65. Ashton, K. That 'Internet of Things' Thing. RFID J. 2009, 22, 97-114.

66. Weiser, M. The Computer for the 21st Century. Sci. Am. 1991, 265, 94-104. [CrossRef]

67. Sharma, N.; Shamkuwar, M.; Singh, I. The History, Present and Future with IoT. In Internet of Things and Big Data Analytics for Smart Generation; Balas, V., Solanki, V., Kumar, R., Khari, M., Eds.; Springer: Cham, Switzerland, 2019; pp. 27-51.

68. Pontin, J. Bill Joy's Six Webs; MIT Technology Review: Massachusetts, MA, USA, 2005.

69. Department, T.C.M.U.C.S. The “Only" Coke Machine on the Internet. Available online: https://www.cs.cmu. edu/ \{\}coke/history_long.txt (accessed on 1 October 2020).

70. Salomon, G. No Distribution without Individual's Cognition: A dynamic Interactional View. In Distributed Cognitions: Psychological and Educational Considerations; Salomon, G., Ed.; Cambridge University Press: Cambridge, UK, 1993; pp. 111-139.

71. McNeill, D. Global firms and smart technologies: IBM and the reduction of cities. Trans. Inst. Br. Geogr. 2015, 40, 562-574. [CrossRef]

72. Söderström, O.; Paasche, T.; Klauser, F. Smart cities as corporate storytelling. City Anal. Urban Trends Cult. Theory Policy Action 2014, 18, 307-320. [CrossRef]

73. Scuotto, V.; Ferraris, A.; Bresciani, S. Internet of Things: Applications and challenges in smart cities. A case study of IBM smart city projects. Bus. Process Manag. J. 2016, 22, 357-367. [CrossRef]

74. Wiig, A. IBM's smart city as techno-utopian policy mobility. City 2015, 19, 258-273. [CrossRef]

75. Wong, P.-H. Three arguments for "responsible users". AI ethics for ordinary people. In Proceedings of the ETHICOMP 2020 Paradigm Shifts in ICT Ethics, Logroño, La Rioja, Spain, 15 June-6 July 2020; Pelegrín-Borondo, J., Arias-Oliva, M., Murata, K., Lara, A.M., Eds.; Universidad de la Rioja: Logroño, La Rioja, Spain, 2020.

76. Oxford English Dictionary. Oxford English Dictionary Online. Available online: https://www.oed.com/ (accessed on 1 October 2020).

77. Butalla, L. The hottest trends in smart labels \& packaging. Convert. Mag. 2004, 22, 46-51.

78. Ellen MacArthur Foundation. Intelligent Assets: Unlocking the Circular Economy Potential; Ellen MacArthur Foundation: Cowes, UK, 2016. 
79. Wang, J.; Lim, M.K.; Zhan, Y.; Wang, X. An intelligent logistics service system for enhancing dispatching operations in an IoT environment. Transp. Res. Part E Logist. Transp. Rev. 2020, 135, 101886. [CrossRef]

80. Safkhani, M.; Rostampour, S.; Bendavid, Y.; Bagheri, N. IoT in medical \& pharmaceutical: Designing lightweight RFID security protocols for ensuring supply chain integrity. Comput. Netw. 2020, 181, 107558. [CrossRef]

81. Schaefer, D.; Cheung, W.M. Smart Packaging: Opportunities and Challenges. Procedia CIRP 2018, 72, 1022-1027. [CrossRef]

82. Brunswicker, S.; Jensen, B.; Song, Z.; Majchrzak, A. Transparency as design choice of open data contests. J. Assoc. Inf. Sci. Technol. 2018, 69, 1205-1222. [CrossRef]

83. Rittel, H.W.J.; Webber, M.M. Dilemmas in a general theory of planning. Policy Sci. 1973. [CrossRef]

84. Kiran, A.H. Responsible Design. A Conceptual Look at Interdependent Design-Use Dynamics. Philos. Technol. 2012, 25, 179-198. [CrossRef]

85. Boenink, M.; Swierstra, T.; Stemerding, D. Anticipating the Interaction between Technology and Morality: A Scenario Study of Experimenting with Humans in Bionanotechnology. Stud. Ethics. Law. Technol. 2010, 4. [CrossRef]

86. Collingridge, D. The Social Control of Technology; Open University: Milton Keynes, UK, 1980.

Publisher's Note: MDPI stays neutral with regard to jurisdictional claims in published maps and institutional affiliations.

(C) 2020 by the authors. Licensee MDPI, Basel, Switzerland. This article is an open access article distributed under the terms and conditions of the Creative Commons Attribution (CC BY) license (http://creativecommons.org/licenses/by/4.0/). 